Ethiopian Journal of Environmental Studies \& Management 7(1): 73 - 81, 2014

ISSN:1998-0507

doi: http://dx.doi.org/10.4314/ejesm.v7i1.9

Submitted: October 31, 2013

Accepted: January 29, 2014

\title{
THE IMPACT OF OBAJANA CEMENT COMPANY AS A GROWTH POLE IN OBAJANA, KOGI STATE, NIGERIA.
}

\author{
*MUSA, D. AND KPANACHE, D. \\ Department of Urban and Regional Planning, Federal University of Technology Minna, Niger State, \\ Nigeria
}

\begin{abstract}
The establishment of Obajana Cement Company in 2003 brought about speedy development in Obajana by deliberately or in-advertently stimulating growth and development at strategic point(s) within the region, though exhibits some problems such as rapid population increase without commensurate provision of facilities, utilities and services, as a result of which planning challenges of various dimensions originate. This research is therefore, carried out with the aim of assessing the spread and multiplier effects of the industry in the region and is fostered by the objectives which examine the pre and post Cement industry, socio spatial and economic spatial development in Obajana and the entire region. It also examines the extent of the multiplier effects induced. The data sourced for the work included primary data, through personal observation, oral interview, questionnaire administration and application of check list in a Focus Group Discussion while the secondary data was sourced from related journals, text books, the internet, news reports and encyclopaedia. The analysis of data was done by computing frequencies, and percentages. Results of analysis are discussed and presented in tables, graphs and pictures. The study found that the region of study is definitely being rapidly transformed economically, socially and physically/spatially. To check this regional development in-balance associated with the establishment of the industry, city development strategy (CDS) planning approach was recommended in all the activities/efforts aimed at fostering balanced and sustainable regional development. This approach is to be applied with paramount regard to the need for equitable regional development practice.
\end{abstract}

Key words: Economic Development, Growth pole, Multiplier effect, Regional development, Spatial development

\section{Introduction}

The project (Obajana Cement Company) is sponsored and owned by Dangote Industries Limited (DIL), a leading producer of cement, sugar, wheat flour and salt in Nigeria. The cement industry was commenced by the Kogi State government which later handed the project over to Dangote group of companies, under the privatisation scheme in the country. In 2003, phase 1 of the Obajana Cement Plant was lunched at a total estimated cost of over US\$ 1 billion and in 2007 it was successfully commissioned. Prior to the commencement of the construction work in February 2003, the population of Obajana community, which was a hamlet by 2002 was estimated to be four hundred (400) (Kpanache, 2009).
In the words of Danladi (2003), in his speech during the takeoff of the company, "the company will produce about twelve (12) million metric tonnes of cement annually at Obajana plant in Kogi State by 2010". This will save the country of huge loss of foreign exchange and would drive down the prices of cement to less than $\$ 6.25 \mathrm{a}$ bag as against the then $\$ 9.37$ and $\$ 12.5$ in 2008 . However, as at November, 2011, the price of cement has increased to $\$ 10.63$

The communities affected by the location of the company include Shagari town which is inhabited by Bassa kwomu people, Oyo Iwa, Nyamaku (Tivs), Wuro Gada Biyu, Wuro Ardo, Wuro Mashu, Wuro Jangale, Zariagi, and Wuro Jahun (Ojile, 2004). Ayodele (2007) in an account of the companys' genesis said the first

*Corresponding Author: Musa, D.

Email: dalilmusa@gmail.com 
phase of the plant, which is reputed to be the most modern and third largest cement factory in the world, has two production lines with a combined full capacity of 15,000 metric tonnes of cement per dayEconomic development is an important and continuous process in the progress of any nation and one important aspect is industrialisation. This is because of the capacity of industries to stimulate growth and development which include; physical, social, environmental and political, over a wide area, from its location, thus serving as growth pole.

The growth pole-growth center theory has been long developed to explain the role of activities of firms, including industries like the one in Obajana in generating and spreading development. When an industry is established, it leads to growth and development spreading spatially from its point of location to adjoining areas and the strength of the spread is dependent on the strength of the industry. When this happens, the industry is said to be serving as a growth pole and the town of its location is the growth center. According to Moses (2004), a growth pole can be identified on the basis of infrastructural development, industrial development and resource frontier, high political and administrative status. The core idea of the growth pole-growth centre theory is that economic development or growth is not uniform over an entire region, but instead more concentrated around a specific pole (Rodrigue, 2009). By definition, Moses (2004) defined growth pole/centre as "a point from which centripetal forces emanate and to which centrifugal forces are attracted, such a point being a point of attraction and repulsion. In another dimension, a growth pole might be a single firm or a group of industries, often characterised by a key industry around which linked industries develop, mainly through direct and indirect effects (Rodrigue, 2009).

The role of small scale mineral exploitation in providing a source of livelihood for millions of the rural and semi-urban African communities cannot be underestimated as exemplified in the lasting role of the gold rush into South Africa as presented by Warren (1998) when he said "the gold rush resources of the Wit-waterstand were discovered in 1886 and were responsible for the rapid growth of Johannesburg which remains the economic core of South Africa". Chapman and Walker (1998) argued further that modern economic growth is driven by productivity increases which in turn, are driven by industrialization in the developing world. Therefore spatial units that are industrialized are more productive and have higher incomes than those that are not industrialized or less industrialized. In other words, geographical variation in industrialization is a primary cause of geographical variation in average income in developing nations, implying that an even distribution will to a reasonable extent warrant balanced regional development. Akande and Idris (2005) say in developing countries, it will continue to provide the needed technological development and employment. Masiku (2008) noted that "large scale mineral exploitation has contributed over $90 \%$ of all foreign exchange earnings, $60 \%$ of Gross National Product (GNP), $50 \%$ of total government revenue and $30 \%$ of total employment in some African countries".

Wanyama and Radhika (2009) analysed that the Obajana cement company project will use locally available limestone, gypsum and natural gas to produce cement at a competitive cost. Therefore, the main impact of the project will be an improved availability of cement at reduced time and financial cost, which will promote needed investments in infrastructure, industrial, commercial and residential construction. In Nigeria, $85 \%$ of consumed cement was imported prior to the establishment of the Obajana Cement Company, despite the fact that raw material deposits for its production abound in the country (Musa, 2009).

The aim of this research is to assess the spread and multiplier effects of Obajana Cement industry, as the growth pole, on adjoining communities and the entire region, with a view to proffering planning recommendations.

The objectives to achieve this aim include to:

i. Assess the socio-spatial and economic development within and around Obajana, the host community before and after the establishment of the cement industry.

ii. Examine the regional extent of the multiplier effects induced by the cement industry in the region. 
This research focuses on Obajana, Oworo district and involves detailed examination of growth pole-growth centre function of Obajana Cement Company in the community and regional development with emphasis on social, economic and physical changes in Obajana and the immediate adjoining localities. It presents the various dimensions of effect of the industry in the development of the region under study.

Scope
The territorial extent of this study is the political boundary of Obajana community. It also covers other communities within $25 \mathrm{~km}$ radius adjoining Obajana (the catchment area). These communities are hereby presented as well as their distances from the host community; Nyamaku $(2.1 \mathrm{~km})$, Wuro Gada biu $(5.1 \mathrm{~km})$, Wuro Ardo $(6.3 \mathrm{~km})$, Oyo iwa $(7.2 \mathrm{~km})$, Wuro Jahun $(7.7 \mathrm{~km})$, Wuro Mashun $(8.5 \mathrm{~km})$, Wuro Jangale $(12.4 \mathrm{~km})$, Zariagi (21.7km) Shagari (27.6km) (Figure 1).

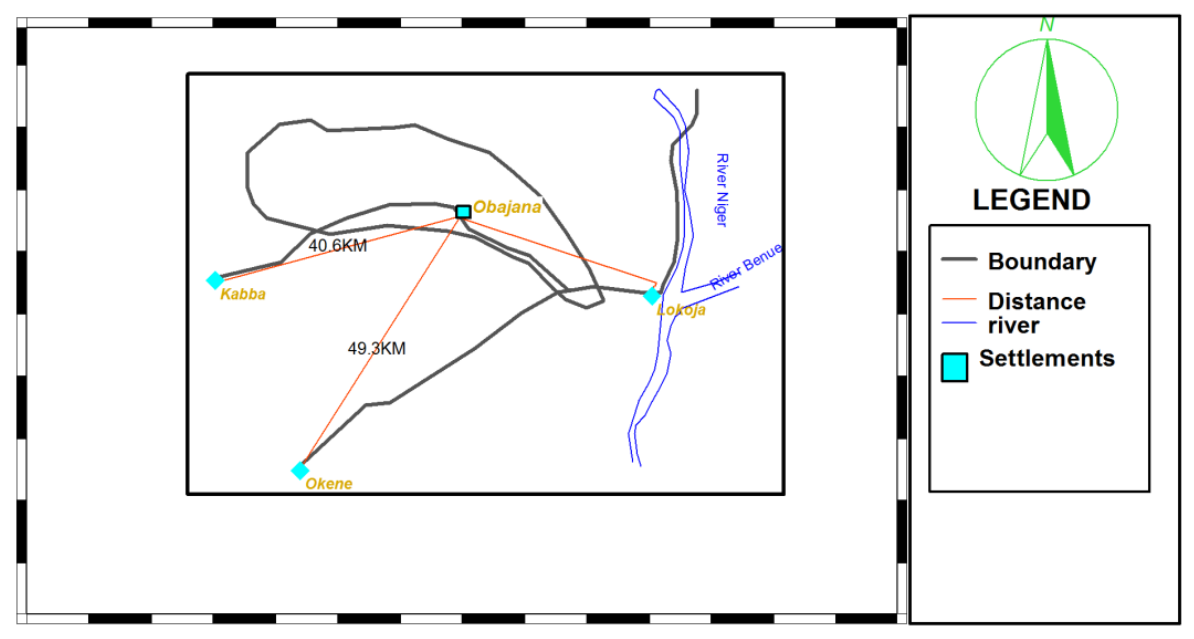

Figure 1: Geographical extent of the study.

\section{Location of the Study Area}

The company is located in Obajana community, Oworo district in Lokoja Local Government Area of Kogi state, Nigeria. It is between Longitudes $7^{\circ} 49^{\prime} \mathrm{N}$ to $8^{\circ} 59^{\prime} \mathrm{N}$; and Latitudes $6^{\circ} 24^{\prime} \mathrm{E}$ to $7^{\circ} 34^{\prime} \mathrm{E}$ (Figure 2). 


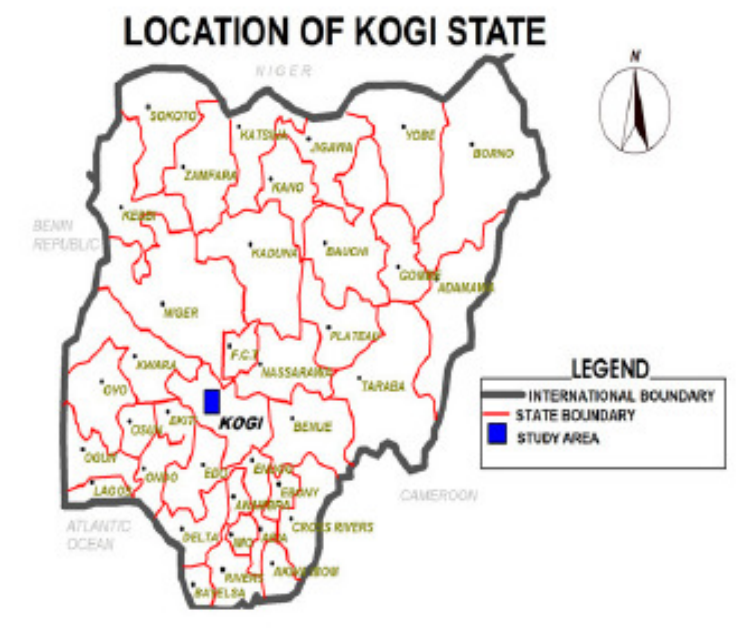

LOCATION OF OBAJANA

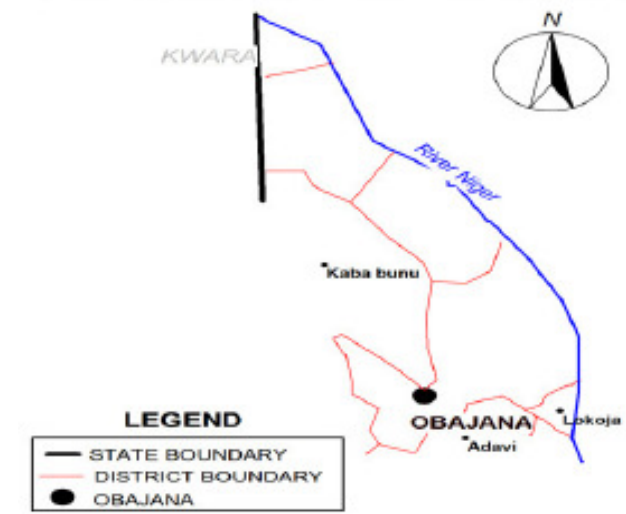

Figure 2: Location of the Study Area

\section{Materials and Methods \\ Sample Frame}

The sample frame employed in this study is of four categories;
a) All adults resident in the settlements within the scope of the study
b) The staff of the company on duty during the data collection period.
c) The wholesale patronisers of the products who are booked during the period of data collection.
d) Adults of age 30 and above in Obajana community and all other villages within the catchment area of the cement industry as indicated in Figure 1.

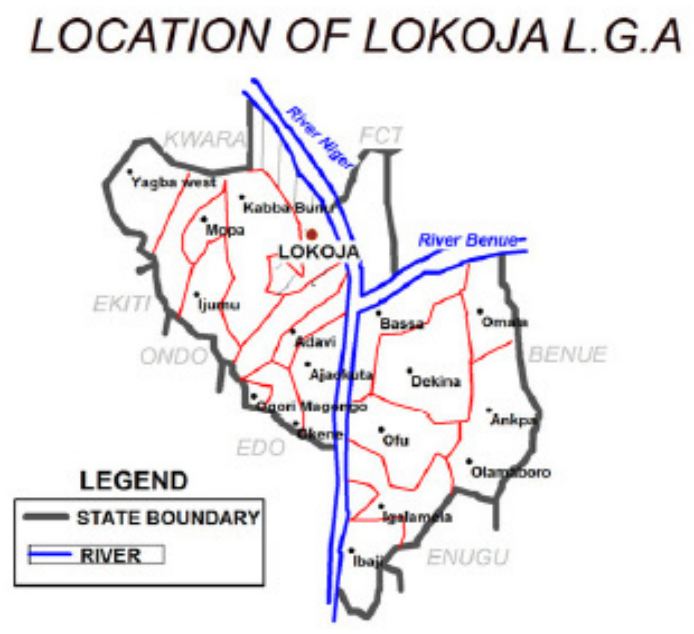

Sample Size

In this research, $5 \%$ of each population category was selected and used for questionnaire administration as indicated below:

\section{Residents Selection}

The sample elements were selected among the residents by systematic sampling. The selection of target elements began from the palace of the chief from which point one household in every other second household was selected. Based on the established criteria of selection that is $5 \%$ of the 6325 Obajana residents, 316 sample elements were selected and used for questionnaire administration. 


\section{Workers selection}

As pertain the workers of the company, stratified random sampling was adopted, using the list of staff on duty during the period of the study to select the sample population from the total list of the employees. Out of the selected 5\% of the workers population, representing 1350 (Total Work force) 68 Sample elements were selected.

The stratification was achieved as presented below:

$40 \%$ for the junior staffs, that is $40 \% \times 68=28$ (Grade Level 1-6)

$30 \%$ for the intermediate staffs, that is $30 \% \times 68$ $=20$ (Grade Level 7-10)

$30 \%$ for the senior staffs, that is $30 \% \times 68=20$ (Grade Level 12-16)

\section{Wholesale Patronisers Selection}

For the whole sale patronisers of the finished products of the company, the main technique used to collect data is systematic random sampling using their sequential booking to locate and select $5 \%$ of the expected 7500 patronisers during the one month period of data collection as the needed number of elements to be administered questionnaire.

The needed sample size for the patronisers is given below:

$5 \% \times 7500$ (Number of expected patronisers per month) $=375$ (Sample elements).

The systematic random sampling was achieved as follows;

375 (Sample elements) $\div 30$ (Days of data collection $)=13($ Sample elements per day $)$
As for the selection guide of the thirteen,

250 (No. of patronisers per day) $\div 13$ (Sample elements) $=19$ (i.e. every $19^{\text {th }}$ element).

This figure implies that daily, every $19^{\text {th }}$ element of the 250 patronisers is to be administered a questionnaire. They were easily assessed at the queue while waiting to be granted access to enter and be served.

On the whole, a total of 759 questionnaires were administered for this study.

Focus Group Discussion Forum: For this purpose, ten (10) adults of the communities within the catchment area of the Obajana Cement Industry responded to the questions contained in the checklist, relating to the effects of the industry in their respective communities.

\section{Results}

Spatial Socio-Economic Development within and around Obajana before and after the Establishment of the Cement Factory.

The analysis of the respondents earnings before the construction of the Cement Company reveals that $34 \%$ had no income at all while $27 \%$ earned $\$ 63$ and less. Only 3\% earned \$250 \$313. About $13 \%$ earned \$131.25 - \$188.

The present situation in Obajana community with regards to the occupancy ratio of households can be said to be average. The research findings presented in Figure 3 shows that 22\% of the respondents have over 6 occupants in a household. A significant size of $32 \%$ have only one or two occupants while those having between 3-6 made up $46 \%$.

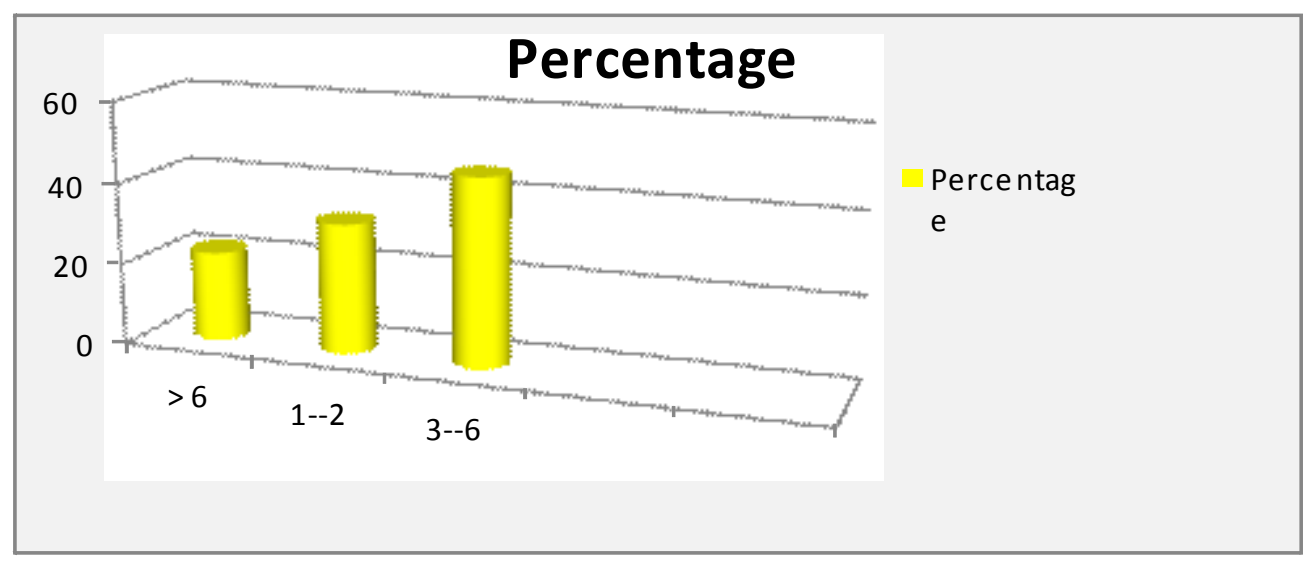

Figure 3: Obajana Residents Household Size Distribution 
Results presented in Figure 4 shows that $\$ 63$ - $\$ 126$ per month is the monthly pay for grade levels $1-7$. The respondents in the average bracket (8-10) constitute $37 \%$ with a monthly pay of between $\$ 131.25$ $\$ 188$. $11 \%$ goes home with monthly pay of between $\$ 194$ to above $\$ 313$. This are the high income earners.

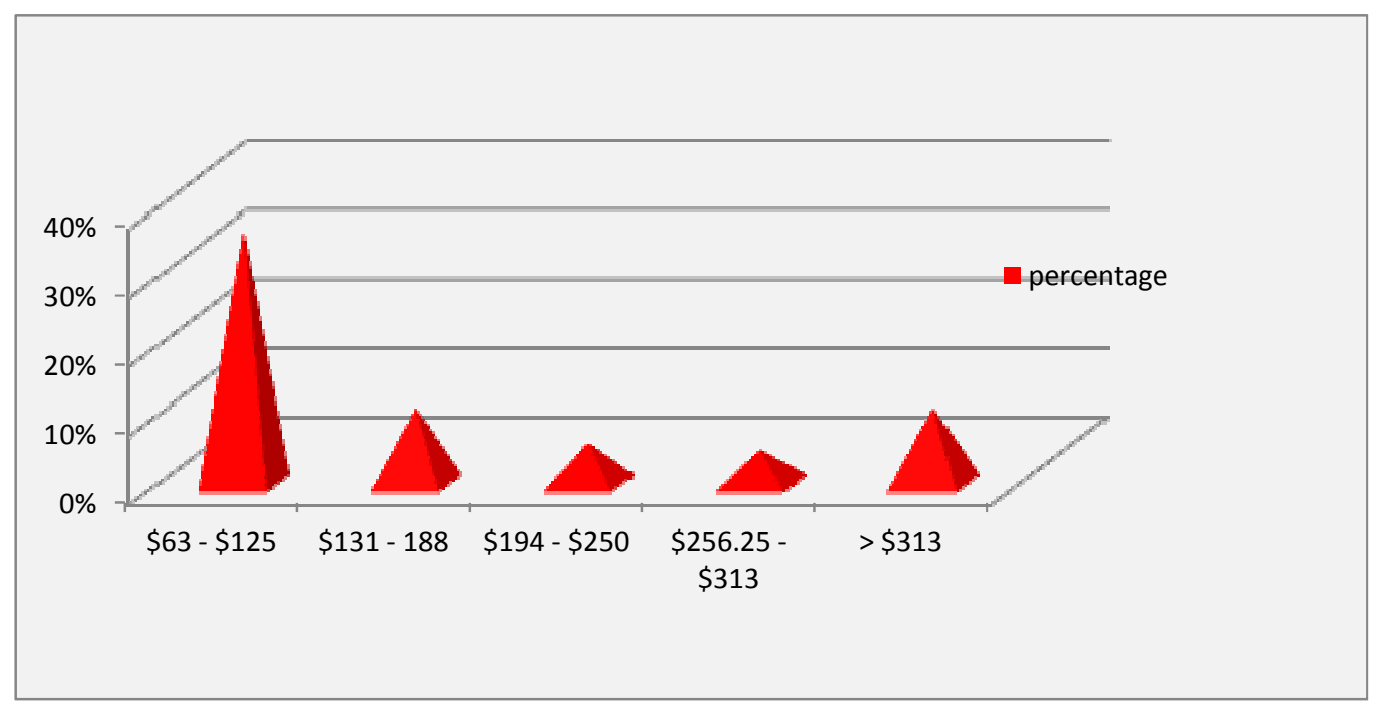

Figure. 4: Monthly Income of Residents

Present Income of Staffs of the Company: It is clear that 55\% earn $\$ 125$ and below, $17 \%$ earn $\$ 131$ - \$188 while 6 people representing 11\%. $\$ 194$ - \$250 The other range in option is $\$ 256-\$ 313$ which is earned by $12 \%$. Last but not the least is the $5 \%$ of the respondents that earn $>\$ 313$. See Figure 5.

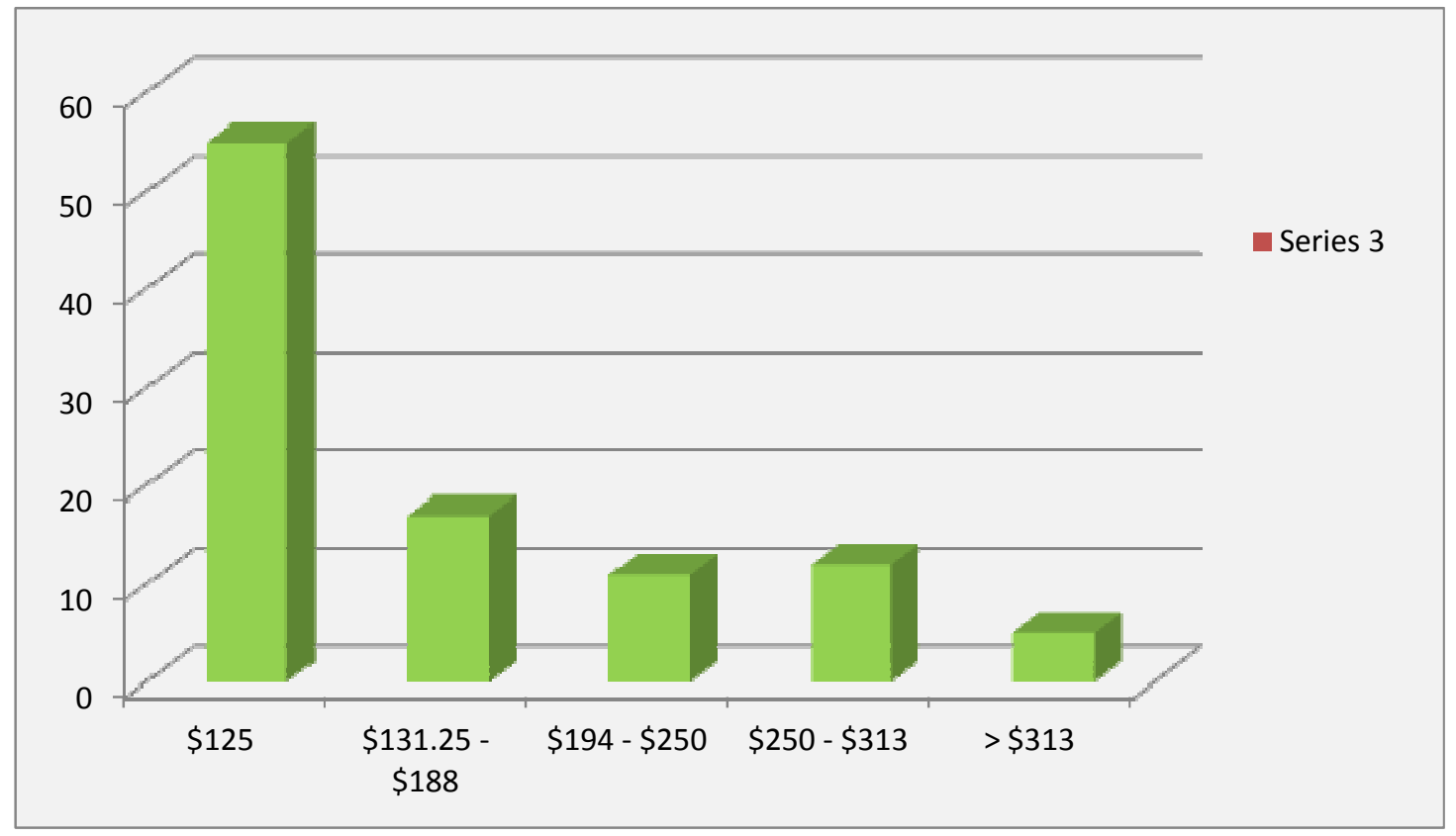

Figure. 5: Average Monthly Income of Staff of the company

Trend in Housing Development: Only 6\% of the present housing stock was built before the coming of the Obajana Cement Industry. Some housing units were built before the industry was established and were modified after its coming. These group makeup $9 \%$ of total housing stock. The majority were 
however built after the company was established, accounting for about $83 \%$ of the total housing stock in the community. See Figure 6:

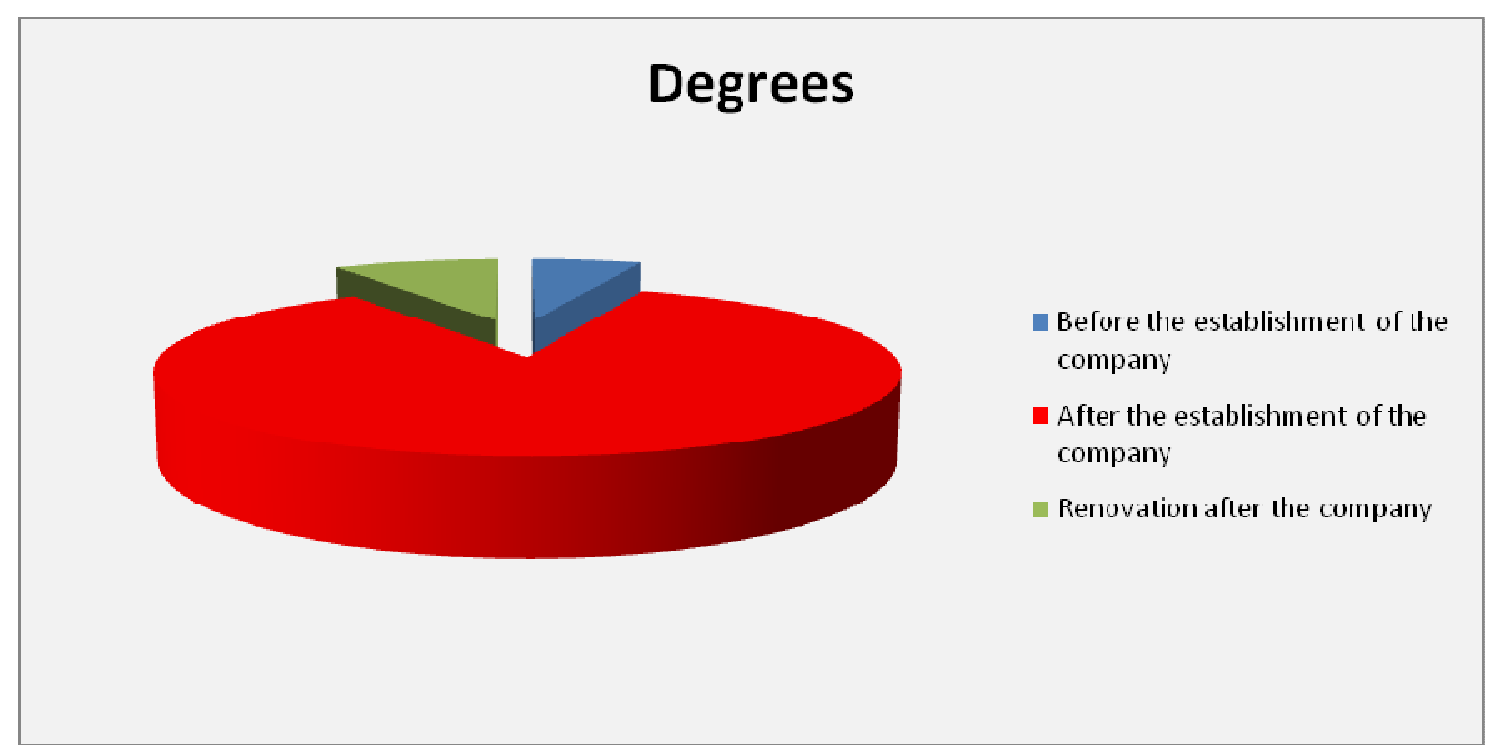

Figure 6: Period Houses were Built

The results have shown that the monthly earnings of the workers of Obajana cement factory has improved significantly. As at present, economically, the staff of the company are at an advantage over their counterparts in the civil service. For instance, the respondents on grade levels 8 -10, monthly earn between \$131.25$\$ 188$, which is equivalent to the earning of workers on grade levels 10-12 in Kogi State Civil Service. Generally speaking, the company gives an advantage to its staff over workers of other public agencies with whom they go to the same market for shopping. Citing the Maxian theory of urbanisation by Karl Max, surplus income, by way of greater monthly earning is a vital stimulant of urbanisation. With this payment to staff of the Company therefore, more money will be available in the community to support socio-economic development.

\section{Regional Extent of Multiplier Effects Induced} by the Cement Industry in the Region

The spread effect of Obajana Cement Industry is measured by the flow of its product as well as all the resultant benefits associated with it. This has been captured by the following questions in the questionnaire administered to the wholesale buyers of the cement product and also by studying the responses of the youths of all the communities that were involved in the focus group discussion.

Destination with the Product: Observing the result in Figure 7 for a trend reveals that the north central region, with a crow distance of between $389 \mathrm{kmW}$ and $648 \mathrm{kmE}$ and about $150 \mathrm{kmN}$ and $72 \mathrm{kmS}$ from Obajana has the highest supply rate with $27 \%$. The South-West $(420 \mathrm{~km})$ has the highest figure of patronage with $14 \%$ followed by the South-South $(398 \mathrm{~km})$ with $8 \%$. The supply to the north east and west, with distances of about $1011 \mathrm{~km}$ and $650 \mathrm{~km}$ account for 17 and $25 \%$ respectively. For the supply to outside other nations with distances greater those already given for the north, south east and west points in Nigeria, only $5 \%$ supply is recorded. 


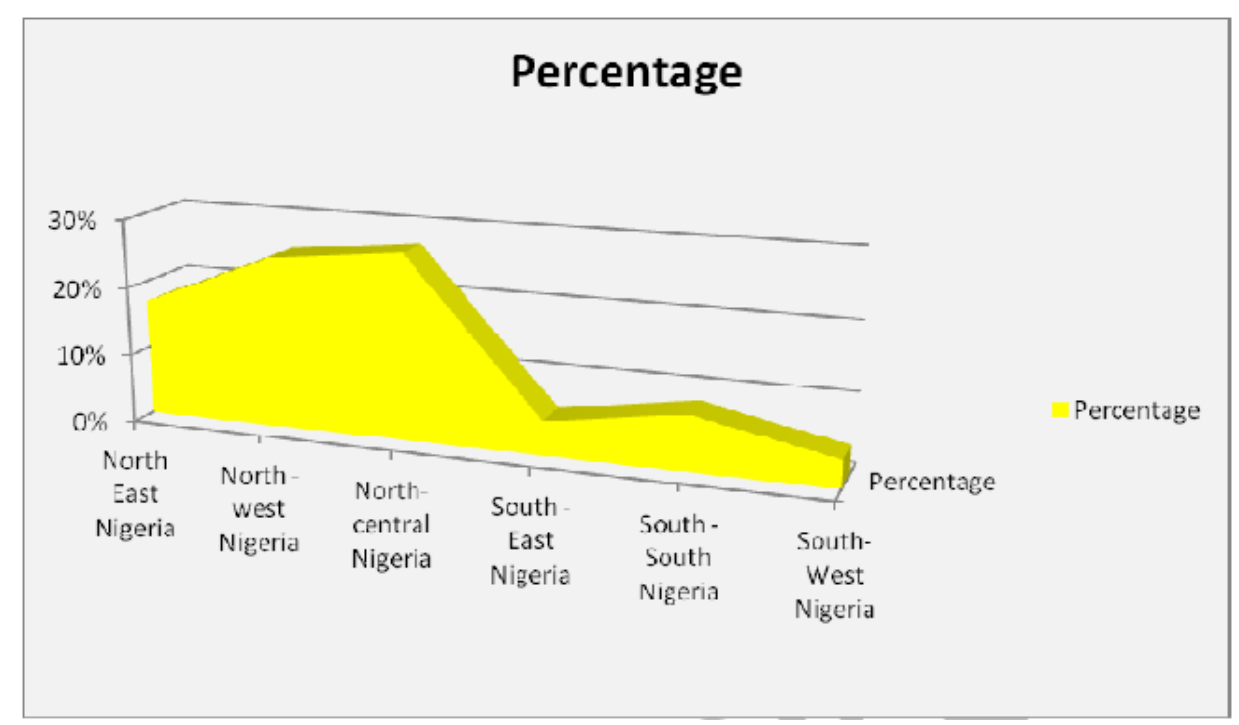

Figure 7: Destination with product

Place of Residence: Only 49\% reside in Obajana while 34\% come to work every day from a farther location from Obajana like Lokoja and Kabba and Okene. Another 17\% live in the immediate neighbouring communities from where they come to work. The data on this is contained in Figure 8.

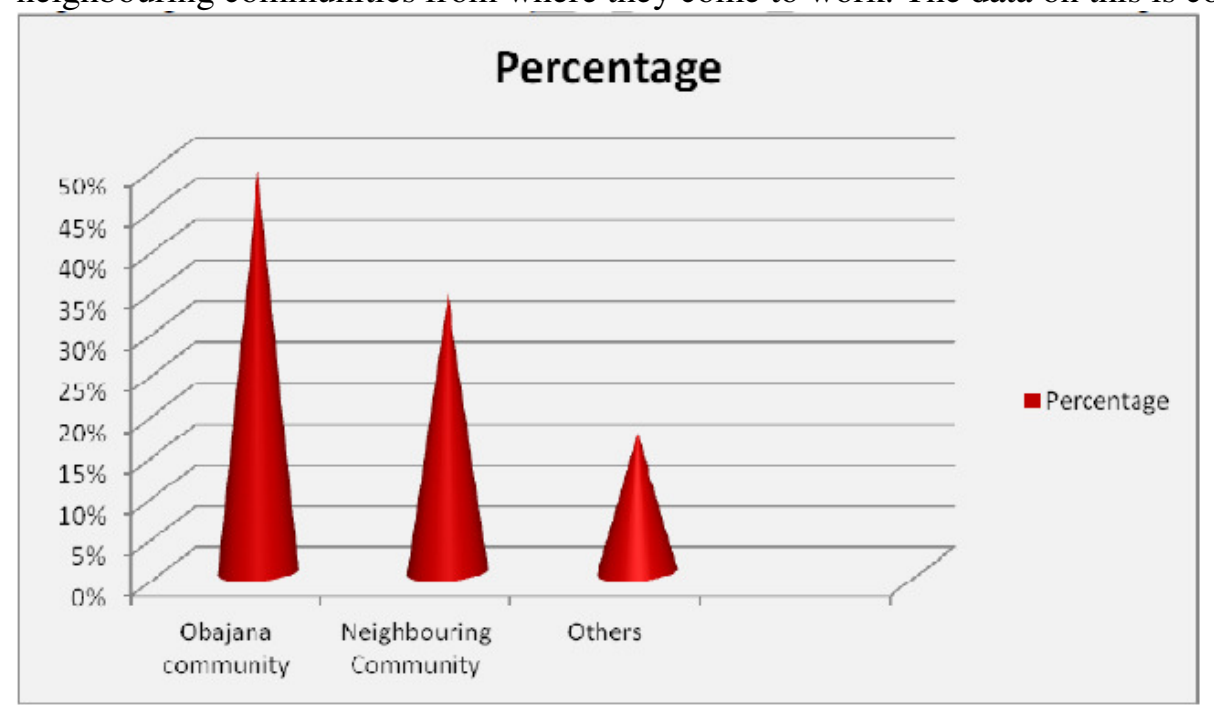

Figure 8: Places of Residence

Obajana community is the beneficiary of significant effects of the established industry. The lifestyle of the residents has shifted from the earlier predominant communal setting to nuclear household setting. Other communities in the region are also benefiting from the social effects of the location of the industry, even though at a reduced rate. In terms of physical or spatial development, the communities in the catchment are the beneficiaries. This development however, begins from the center of location (Obajana) from where it spread outward. A good example of this is the aspect of housing. Economically, the whole of Nigeria is impacted.

The impacts vary and include the fact that the product of this company is available in every part of Nigeria and beyond. This goes to say that the company is satisfying needs, and creating employment opportunities to the people within and outside study area. 


\section{Conclusion}

There is a significant change in the physical, social and economic environment of Obajana community since the cement industry initiated various activities, on establishment in 2003 . This significant transformation however has eluded most of the adjoining settlements within the region of location of its location. There is also a nationwide impact of the company through the availability of its product in different regional economies and actively participating in shaping these markets. It is a globally accepted fact that growth poles are catalyst of or stimulates the growth and development of a region in a diverse ways. The siting of Obajana Cement Company in that community does not deviate from this long known fact.

\section{Recommendations}

From the results of this research carried out on the analysis of impact of Obajana Cement Company on the region, the baseline recommendation is that for efficient results, the City Development Strategy (CDS) should be applied in all recommended actions for management of the effects of Obajana cement industry. The CDS simply is an approach to planning which solicits for bottom-up planning for societies. This system of planning originates from the people concerned. They define their problems, identify their preferred ways of tackling the problems as well as actively involved in the commitment of resources. However, the need for co-ordination by experts cannot be overemphasized.

With regards to the examination of the major physical transformation of the host community and the region, and in line with the tenets of City Development Strategy (CDS), the establishment of the company necessitates with urgency the preparation of an action area plan or master plan preparation for the communities and region at large. The regional plan is for the settlements within the catchment area (Action Areas Plan) and development area plan for the host community recommended.

\section{References}

Akande, J. M. and Idris M. A.(2005). Enverionemntal Effects of Gemstone
Exploration in Oyo State Nigeria. International Journal of Science Engineering and Technology, Vol. 12(1).

Chapman, K. and Walker, D. F. (1998). Industrial Location Principles and Polices. Oxford Publishers, Blackwell Pp 56 - 57.

Danladi, K. (2003). Towards an Industrial Development of the Nigerian Economic Sector. A Speech Delivered at the Post Annual General Meeting Luncheon Talk on the Industrial Sector at the conference Hall, Ibro Hotel Abuja, July, 2003.

Ibrahim, M. (2007). Regional Development Potentials in Kogi State Nigeria. An unpublished B.Tech Degree Research Work. Department of Urban and Regional Planning, Federal University of Technology, Minna. Nigeria.

Kpanache, D. (2009). Growth pole impact of Obajana Cement Company in Kogi State, Nigeria An unpublished M.Tech Thesis Federal University of Technology, Minna Nigeria Department of Urban and Regional Planning.

Masiku, A. N. (2008). Economic, Environmental and Social Impact of Small Scale Minning. http:www.32.org 2 May, 2009..

Moses, G. (2004). Regional Development Planning in Nigeria. An unpublished B.Tech. Degree Field Work, Department of Urban and Regional Planning Federal University of Technology, Minna, Nigeria.

Musa, D. (2009). Economic Potentiioals of Obajana cement company. Undergraduate lecture Material. Department of Urban and Regional Planning Federal University of Technology, Minna. Nigeria.

Ojile, K.C. (2004). Perspective of Regional Development in Obajana. A paper presented at the Workshop on Regional growth and Development, Lugard Hall Kaduna, May, 2004.

Rodrique, E. (2009): Economic Development Opportunities; Employment Opportunities in Central New York region, US Census data inc. www.doctor.com/doc/11090439/centre.

Wanyama, M. and Radhika, S. (2009). Summary of Project Information, International Finance Coroperation Projects. Washington DC MWanyama@ifc.org 23/9/2008.

Warren, K. (1998). Mineral Resources Exploration in South Africa. David Charles Ltd Brazil. Applied Geography, 10 pp75 78. 